\title{
Self-sustaining infrapopulation or colony? Redial clonal groups of Himasthla elongata (Mehlis, 1831) (Trematoda: Echinostomatidae) in Littorina littorea (Linnaeus) (Gastropoda: Littorinidae) do not support the concept of eusocial colonies in trematodes
}

\author{
Kirill V. Galaktionov ${ }^{1,2,3}$, Irina M. Podvyaznaya ${ }^{1}$, Kirill E. Nikolaev ${ }^{2}$ and Ivan A. Levakin ${ }^{1}$ \\ ${ }^{1}$ Laboratory of Parasitic Worms, Zoological Institute, Russian Academy of Sciences, St. Petersburg, Russia; \\ ${ }^{2}$ White Sea Biological Station, Zoological Institute, Russian Academy of Sciences, St. Petersburg, Russia; \\ ${ }^{3}$ Department of Invertebrate Zoology, St. Petersburg State University, St. Petersburg, Russia
}

\begin{abstract}
Trematode sporocysts and rediae reproduce by parthenogenesis, forming clonal groups in the molluscan host. It has recently become popular to consider these groups as eusocial colonies, with division of labour between rediae morphs: small 'soldiers' incapable of reproduction defend the colony, while large rediae reproduce. Alternatively, clonal groups can be considered as self-sustaining infrapopulations. We tested these two hypotheses in the light of new data on rediae of Himasthla elongata (Mehlis, 1831) from snails Littorina littorea (Linnaeus) concerning ultrastructure, growth character and composition of their groups. Clonal groups under study contained rediae of different age and maturity stages: small (young) rediae, rediae with early cercarial embryos, rediae with late embryonic cercariae, rediae with fully formed motile cercariae, rediae with redial embryos and degenerating rediae. Small rediae had a reproductive organ, the germinal mass, whereas most large rediae with developing cercariae did not, which contradicts the eusocialconcept. Overall distribution of rediae by size and by gut to body length ratio was bimodal, which agrees with the eusocial concept ('soldiers' and 'reproductives' as modal size classes). On closer inspection, however, the bimodal size-frequency distributions (SFD) turned out to be the sum of unimodal SFD of rediae at various stages of maturity. The overall bimodality was determined by the character of redial growth resulting in a relatively low occurrence of intermediate morphs and by the developmental arrest in young rediae. The facts that small rediae can attack other rediae and concentrate in the anterior parts of the mollusc can be explained by age-related feeding preferences and niche segregation. They are unlikely to be associated with the 'colony' defence against invaders. To sum up, clonal groups of $H$. elongata rediae in our study represented self-sustaining infrapopulations. We failed to find any arguments in favour of their eusocial organisation.
\end{abstract}

Keywords: rediae, parthenitae, Digenea, eusociality, castes, germinal mass, reproduction, allometry, developmental arrest, feeding behaviour

The life cycles of trematodes are uniquely diverse yet all these parasites reproduce parthenogenetically in the first intermediate host, the mollusc (see for reviews Dobrovolskij and Ataev 2003, Galaktionov and Dobrovolskij 2003). The miracidium infects the mollusc (in Aporocotylidae, the polychaete - see Køie 1982, Cribb et al. 2011), where it develops into a mother sporocyst. The latter reproduces by apomictic parthenogenesis and produces the daughter parthenogenetic generation genetically identical to the mother sporocyst. The daughter parthenitae, which may be represented by rediae or by daughter sporocysts, reproduce parthenogenetically to produce the next generation of parthenitae and/or cercariae. Cercariae are disper- sive larvae capable of infecting the downstream (second intermediate or final) host.

In most trematode taxa, parthenitae form clonal groups in the molluscan host. These clonal groups may be self-sustaining or not self-sustaining (see for review Galaktionov and Dobrovolskij 2003, Ataev et al. 2005, Galaktionov et al. 2014). Self-sustaining clonal groups are characteristic of redioid and sporocystoid trematodes, whose rediae/ daughter sporocysts may produce not only cercariae but also parthenitae of the next generation (Allocreadiidae, Clinostomidae, Echinostomatidae, Fasciolidae, Gastrothylacidae, Paragonimidae, Paramphistomatidae, etc. and at least many of the Diplostomoidea and Schistosomatoidea). 
Non-self-sustaining clonal groups are found in many Plagiorchiida (Microphalloidea, Opisthorchioidea, Plagiorchioidea, etc.), which have only two parthenogenetic generations - the mother and the daughter sporocyst.

Self-sustaining clonal groups are referred to as self-reproducing or self-sustaining infrapopulations (SSI) (Galaktionov and Dobrovolskij 2003). During their lifetime in the molluscan host they are repopulated: old individuals die and young ones, produced by the parthenitae of the previous generations, take their place. The dynamics of SSI demographic composition is complex and species-specific. The number of parthenogenetic generations may be virtually unlimited, as in species of Schistosoma Weinland, 1858 and some species of the Echinostomatidae and Philophthalmidae (see Dönges 1971, Théron 1981, Touassem and Théron 1986, Dönges and Gotzelmann 1988, Ataev and Dobrovolskij 1990), or limited, as in the Cyclocoelidae (see Ginetsinskaya 1954, Taft 1973, Taft and Heard 1978) and the Fasciolidae (see Belfaiza et al. 2004, Rondelaud et al. 2004, 2009). Demographic processes are also influenced by the size and physiological state of the molluscan host and abiotic factors, especially temperature (Dinnik and Dinnik 1963, 1964, Ataev 1991).

It has recently been suggested that SSI of rediae may have eusocial organisation, with the division of labour between colony members (Hechinger et al. 2011, Leung and Poulin 2011). These ideas were based on significant size differences between two 'castes' of rediae and the virtual absence of intermediate morphs (size-frequency distribution of rediae in the colony turned out to be bimodal). According to this concept, small rediae, which are referred to as 'soldiers' (secondary morphs, mini-rediae), do not reproduce and are specialised in defending the colony from conspecific and heterospecific invaders. These small rediae, with a well-developed pharynx and locomotory extensions, actively attack invaders. They concentrate in the anterior parts of the molluscs (mostly lacunae of the mantle), where invasions usually occur. The reproductive function in the colony is performed by large individuals, the so-called reproductive or cercaria-producing rediae. Redial colonies have been described in Himasthla elongata (Mehlis, 1831), Himasthla sp. B, Acanthoparyphium sp. (Echinostomatidae), Philophthalmus sp. and two unidentified species of the Philophthalmidae (Hechinger et al. 2011, Leung and Poulin 2011, Miura 2012, Lloyd and Poulin 2013, Nielsen et al. 2014).

Eusociality in flatworms hit the scientific headlines and the idea has caught up (e.g. Newey and Keller 2010, Zoology: cooperative flatworms 2010, Gunn and Pitt 2012). At the same time, the arguments in favour of eusocial organisation of redial clonal groups do not agree or do not quite agree with the results of some other studies (Zikmundová 2011, Galaktionov et al. 2014, Gorbushin and Borisova 2014).

The aim of our research was to analyse the parameters of the clonal groups formed by the rediae of the echinostomatid trematode Himasthla elongata in the light of the traditional ideas of SSI and in the light of the eusociality concept. The species chosen is congeneric with Himasthla sp. B, for which social organisation of rediae was first described (Hechinger et al. 2011). Since the eusociality concept is to a large extent based on the inability of the 'soldier caste' to reproduce, we paid special attention to the analysis of the morphological and functional organisation of the rediae of different size focussing on the structures associated with the reproductive function (germinal mass and brood chamber). Our research also focussed on the analysis of the redial growth and size-frequency distributions of rediae in clonal groups.

\section{MATERIALS AND METHODS}

\section{Material collection and processing}

The research was carried out at the White Sea Biological Station of the Zoological Institute of the Russian Academy of Sciences situated in the Chupa Inlet, the Kandalaksha Bay of the White Sea $\left(66^{\circ} 20^{\prime} \mathrm{N} ; 33^{\circ} 38^{\prime} \mathrm{E}\right)$. Periwinkles Littorina littorea (Linnaeus) infected with rediae of Himasthla elongata were collected in the intertidal zone in the vicinity of the Station in 2011-2013. We selected snails with shell height of 23-28 mm, which, as shown in previous investigations, were most likely to be infected with H. elongata. Periwinkles were placed in $100 \mathrm{ml}$ plastic jars filled with seawater (one periwinkle per jar) and left in sunlight for 1 $h$. The jars were then examined under a stereomicroscope and individuals that had shed cercariae of $H$. elongata were selected.

Some of these periwinkles were maintained in the laboratory in seawater at $5^{\circ} \mathrm{C}$ for maximum $1 \mathrm{wk}$ prior to dissection. The molluscs were dissected and infections with parthenitae of $H$. elongata were recorded. If a snail was found to be infected, three fragments ( $c a 200 \mathrm{~mm}^{3}$ each) of its visceral sac were cut out: the basal part with the adjoining areas of the mantle and the kidney (zone 1), the middle part (gonad/digestive gland complex) (zone 2) and the apical part (digestive gland) (zone 3). In total, these fragments made up $1 / 15-1 / 20$ of the visceral sac, where the redial clonal group was located. Additionally, we scanned the snail's mantle, the anterior complex of organs (head, ctenidium) and the foot.

The visceral sac fragments obtained from the infected snails were placed separately in Petri dishes with seawater and all rediae were extracted from them with the help of fine preparation needles under a stereomicroscope at magnification of $40 \times$. Each of these rediae was then placed on an object slide, immobilised by pressing slightly with a coverslip and examined under a light microscope at magnifications of 100-200×. All of the rediae examined in vivo were classified into six morphologically different types (for their description see Results). Rediae of the same type were counted in each visceral sac fragment. Altogether 18 redial clonal groups were analysed. Body length and width were measured in some rediae (33-34 randomly selected individuals from each fragment) from six clonal groups. In case of one snail, all rediae from all three selected visceral sac fragments were measured. Living rediae chosen for measuring were placed on an object slide, pressed lightly with a coverslip and measured under the microscope. Altogether, 929 rediae were measured. 


\section{Determining the lifespan of redial clonal groups of Himasthla elongata}

In 2010 some $L$. littorea infected with rediae of $H$. elongata were placed into a net cage and kept all year round in the subtidal zone near the Station at a distance of $15 \mathrm{~m}$ off the shore. The cage, moored with a deadweight anchor, was placed at a depth of ca $3.5 \mathrm{~m}$ and at a distance of $c a 5 \mathrm{~m}$ from the bottom. Under such conditions spontaneous infection by miracidia of $H$. elongata is impossible.

Periwinkles were fed on Enteromorpha sp. seaweed and of thalli decayed Fucus vesiculosus and Laminaria saccharina. Twice a year the cage was taken out, the dead individuals were counted and the survivors checked for ability to shed cercariae using the above scheme. This ability served to indicate that redial clonal groups were viable. After the check the snails were returned to the cage.

\section{Morphological studies}

In vivo light microscopic observations of rediae were made with the help of an Olympus CH-40 microscope. Microphotographs were made with the use of the same microscope equipped with an Olympus XC-30 digital camera. For TEM studies the rediae were fixed in $4 \%$ glutaraldehyde buffered with $0.1 \mathrm{M}$ sodium cacodylate $(\mathrm{pH}=7.4)$ at $4{ }^{\circ} \mathrm{C}$. After $10-14$ days the samples were rinsed in $0.1 \mathrm{M}$ cacodylate buffer $(3 \mathrm{~h})$ and post-fixed with $1 \% \mathrm{OsO}_{4}$ in the same buffer $\left(2 \mathrm{~h}\right.$ at $\left.4{ }^{\circ} \mathrm{C}\right)$. Sucrose was added to the fixatives and the rinsing buffer to adjust the osmolarity of the solutions to $760 \mathrm{mOsm}$. After fixation, rediae were dehydrated in an ascending ethanol series and acetone and then embedded into Epon-Araldite mixture. Ultrathin and semithin longitudinal sections were made with the Leica EM UC6rt ultramicrotome. Ultrathin sections were stained with aqueous solution of uranyl acetate and lead citrate after Reynolds (1963) and viewed in the transmission electron microscope Morgagni 268 at $80 \mathrm{kV}$. Semithin sections were stained with toluidine blue and examined under the Leica DMLS light microscope. We studied series of alternating semithin and thin sections of five small rediae (isolated from the lacunae of the mantle and the kidney) and four large rediae (from the gonad/hepatopancreas) filled with well-developed motile cercariae. In addition, we re-examined grids with sections of two middle-sized rediae used earlier for the analysis of the germinal mass ultrastructure (Podvyaznaya and Galaktionov 2014).

\section{Data analysis}

When analysing the size parameters of rediae, we pooled the data on all individuals of the same redial type from all the clonal groups under study. We calculated the volume of the redial body $(V)$ approximating the shape of the redia to a cylinder: $V=\pi l(w / 2)^{2}$, where $l$ is body length and $w$ is body width (= $h$ is body height). As rediae of $H$. elongata are highly contractile, we used, besides the body length and width, also the standard linear size (SLS) calculated as a geometric mean (Sokal and Rolf 1995) of three linear measurements: SLS $=(l w h)^{1 / 3}$ or SLS $=\left(l w^{2}\right)^{1 / 3}$.

Apparently, SLS is directly proportional to the cubic root of the volume $\left(\mathrm{SLS}=k V^{1 / 3}\right.$, where $\left.k=(4 / \pi)^{1 / 3}\right)$, and the distribution of rediae by any linear size (in particular SLS) is, by definition, less skewed than by volume $(V)$. Therefore, we used SLS instead of the body volume $(V)$ for the assessment of size-frequency dis- tribution of rediae in the clonal groups. All dimensional parameters (except scale bars) are given in $\mathrm{mm}$ or $\mathrm{mm}^{3}$.

To assess the body shape ('plumpness') of rediae, the relative body width, i.e. the ratio of body width to body length, was used. The degree of development of the digestive system was assessed using the relative gut length, i.e. the ratio of gut length to body length. To compare the occupancy of various parts of the visceral sac of L. littorea with rediae of H. elongata, we calculated the total volume occupied by the rediae for each analysed fragment. For this, the number of rediae of a given type was multiplied by the average body volume of this redial type, and the total volume was calculated as a sum of these products.

The data were treated statistically according to the standard recommendations (Sokal and Rohlf 1995). When constructing size-frequency histograms, the size of class intervals $(h)$ was determined according to Scott (1979): $h=3.49 S n^{-1 / 3}$, where $S$ - standard deviation of the sample and $n$ - sample size. As the distributions of characters related to redial size and body shape were far from normal and often had an expressed and differently directed skewness (asymmetry coefficient $|A s|>0.5$ ), a robust median test was used in statistical comparisons. Average values and confidence intervals of the average values (given in parentheses in the text) of these characters were calculated via Box-Cox data transformation. All confidence intervals were calculated for the $95 \%$ significance level. Differences in the proportions of redial types in different parts of the visceral sac were assessed with the help of one-way ANOVA for arcsin-transformed proportions.

\section{RESULTS}

\section{Morphology of the rediae}

Small rediae of Himasthla elongata are actively moving organisms with a narrow elongated body (Fig. 1), a collar in the anterior part and two locomotory extensions in the posterior part. Their pharynx is well developed and the gut occupies most of the body, reaching the level of locomotory extensions (Fig. 1). The excretory formula is $2[(2+2)$ $+(2+2)]=16$. All small rediae examined under light and electron microscope had a well-developed germinal mass just posterior to the gut. The germinal mass was quite distinct even in the youngest rediae that could be discerned within large ones (see below) (Fig. 1A).

The germinal mass could also be clearly seen during in vivo examination of individuals under slight pressure of a coverslip, when the posterior part of the redia was somewhat distended (Fig. 2A-C). Most small rediae examined completely lacked body cavity (= brood chamber), their germinal mass being surrounded by several layers of parenchymal cell outgrowths (Fig. 2D,E). The posterior conical body part and the locomotory extensions were densely packed with parenchymal, muscular and tegumental cells.

In some small rediae, the germinal mass consisted only of stem cells, germinal cells and supporting cells and did not include any early embryos of the next generation (Fig. 2D). In this case the cell bodies were located at the periphery of the germinal mass, whereas its central part was filled with the outgrowths of the supporting cells, with singular pyknotic bodies among them. Fine structure of the stem cells, germinal cells and supporting cells was iden- 


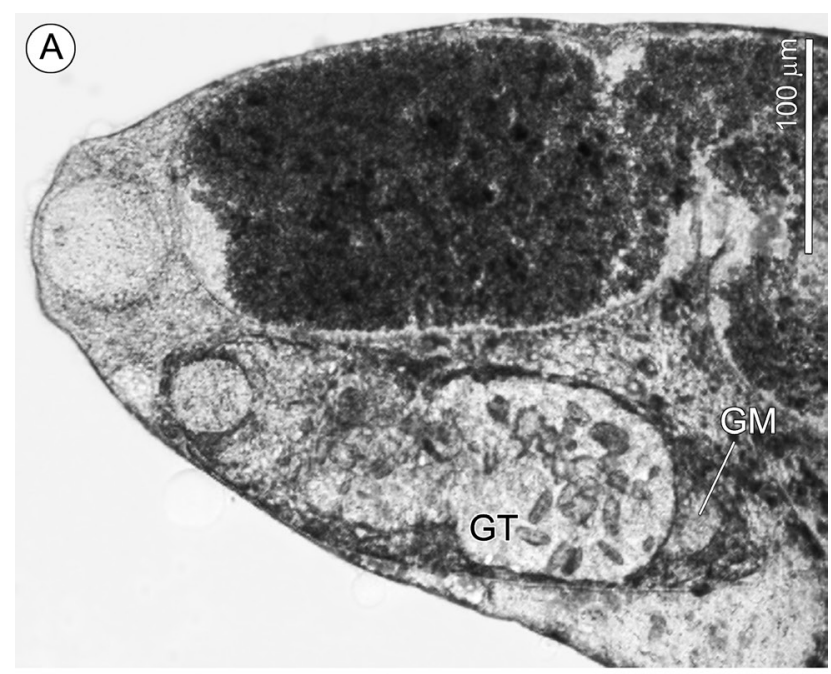

(B)
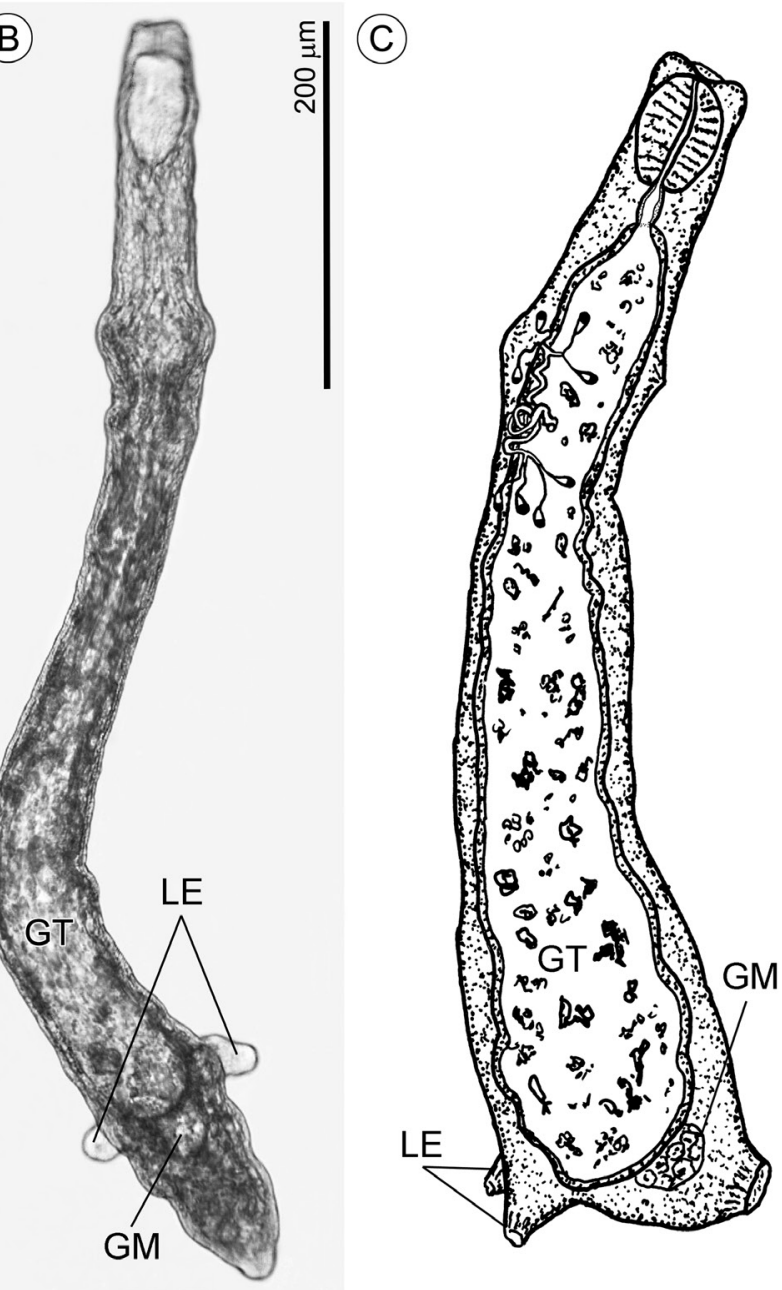

Fig. 1. Small rediae of Himasthla elongata (Mehlis, 1831) from Littorina littorea (Linnaeus). A - light microscopic image of small redia inside the mother individual; $\mathbf{B}$ - light microscopic image of small living redia; $\mathbf{C}$ - scheme showing structure of small redia. Abbreviations: GM - germinal mass; GT - gut; LE - lateral extensions; YR - small (young) redia.

tical to that observed in middle-sized rediae of $H$. elongata (see Podvyaznaya and Galaktionov 2014), which contained germinal balls and a few embryonic cercariae at early stages of morphogenesis.
In most small rediae studied, the germinal mass contained from one to three early embryos of the next generation (Fig. 2E). They could be at the stage of a 'naked cell aggregate', at the stage of primitive epithelium formation or at the stage of an early germinal ball. These embryos were surrounded with outgrowths of the supporting cells, whose perikarya were pressed back from the periphery of the germinal mass into its central part by the developing embryos and maturing germinal cells (Fig. 2E). Sometimes early germinal balls with a well-developed primitive epithelium lay outside the germinal mass, being separated from it by a narrow slit-like intercellular space filled with some residual material (Fig. 3A). These embryos as well as the germinal mass were surrounded by the parenchymal cell outgrowths.

Among small rediae examined, a few contained 2-3 germinal balls completely separated from the germinal mass (Figs. 2C, 3B). TEM showed that these embryos lay in a small incipient body cavity situated near the posterior end of the gut and surrounding most of the germinal mass (Fig. 3B). The cavity was lined by loose and irregularly arranged outgrowths of parenchymal cells. Some of these outgrowths formed fine septa separating the cavity into sections (Fig. 3B). Most of the posterior body part and locomotory extensions in such rediae was, similarly to the above-described cases, filled with parenchymal, muscular and tegumental cells and their outgrowths, which in the vicinity of the incipient body cavity were separated by rather broad intercellular spaces (Fig. 3B). The outer tegumental layer of the small rediae was covered with microvilli-like projections, its apical plasma membrane also formed numerous small, rounded invaginations, resembling pinocytotic vesicles in the process of formation (Fig. 3C). The tegumental cytoplasm contained mitochondria and secretory granules transported there from the cytons.

Middle-sized rediae of $H$. elongata containing germinal balls and early embryonic cercariae (Fig. 4A,B) had a well-expressed body cavity, which was not separated into sections. It occupied most of the posterior part of the redial body, entered the locomotory extensions and protruded forwards parallel to the gut up to the level of the pharynx. The parenchymal cell outgrowths limiting the body cavity were arranged in parallel layers. Germinal masses of such rediae were described in detail by Podvyaznaya and Galaktionov (2014). Their composition indicated a simultaneous unfolding of several processes, including the multiplication of the germinal cells, their maturation and the formation of early embryos of the next-generation individuals. The embryos left the germinal mass at the stage of an early germinal ball to continue their development in the body cavity.

In large rediae with a vast body cavity, densely packed with well-developed motile cercariae (Fig. 4C), the germinal mass was found only in one of the four individuals studied in serial sections. On the whole, the germinal mass was similar to that in the middle-sized rediae (see above) but smaller $(45 \times 18 \mu \mathrm{m} v s 55 \times 25 \mu \mathrm{m})$ and contained fewer early embryos. Some small germinal balls were found near this germinal mass in the body cavity. In large rediae 

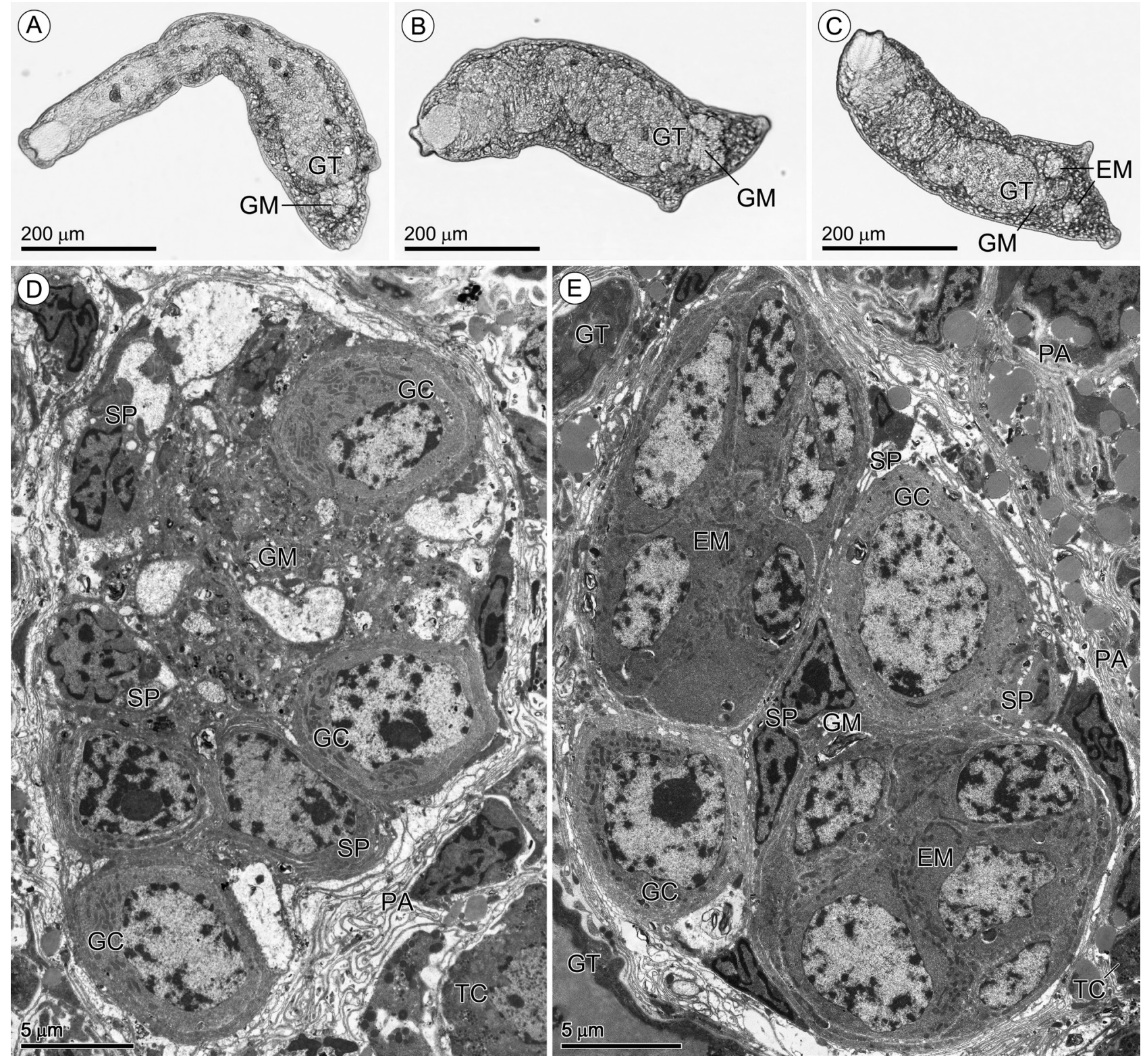

Fig. 2. Germinal mass in small rediae of Himasthla elongata (Mehlis, 1831) from Littorina littorea (Linnaeus). A-C - light microscopic images of living rediae with germinal mass immediately posterior to the gut. Note early embryos near the germinal mass in one of the specimens; D - transmission electron micrograph of a germinal mass containing no early embryos; $\mathbf{E}$ - transmission electron micrograph of a germinal mass containing early embryos. Abbreviations: EM - early embryo; GC - germinal cell; GM - germinal mass; GT - gut; PA - parenchymal cell; SP - supporting cell; TC - tegumental cell.

without the germinal mass, germinal balls were revealed only sporadically. The body wall of large rediae was rather thin, subtegumental cells composing the body wall were densely packed and the covering epithelium had the same structure as in small rediae.

\section{Composition of redial clonal groups, their location and lifespan in the molluscan host}

In clonal groups, rediae of $H$. elongata differed in their size parameters, morphological features and reproductive status. They were classified into six types, which we identify with the following consecutive developmental stages:

(i) Small (young) rediae (YR), sometimes containing few germinal balls. Small-sized rediae, 0.17-0.91 $\mathrm{mm} \times$
0.04-0.6 mm, with a well-developed gut, 0.15-0.85 mm long, always reaching the level of locomotory extensions (Figs. 1B,C, 2A-C). Body cavity is absent or fairly small, incipient with a few germinal balls.

(ii) Rediae with early cercarial embryos (RCE). Somewhat larger rediae, $0.3-2.1 \mathrm{~mm} \times 0.08-0.90 \mathrm{~mm}$, with a well-developed gut, 0.18-1.59 mm long, which may not reach the level of locomotory extensions (Fig. 4A,B). Body cavity is well-expressed and contains not only germinal balls but also early embryonic cercariae (tail bud stage).

(iii) Rediae with late embryonic cercariae (RC). Large rediae, $0.25-3.18 \mathrm{~mm} \times 0.1-1.35 \mathrm{~mm}$, with a well-developed body cavity usually containing numerous cercarial embryos at different stages of development and some almost fully-formed, though immotile, cercariae (Fig. 4D). 

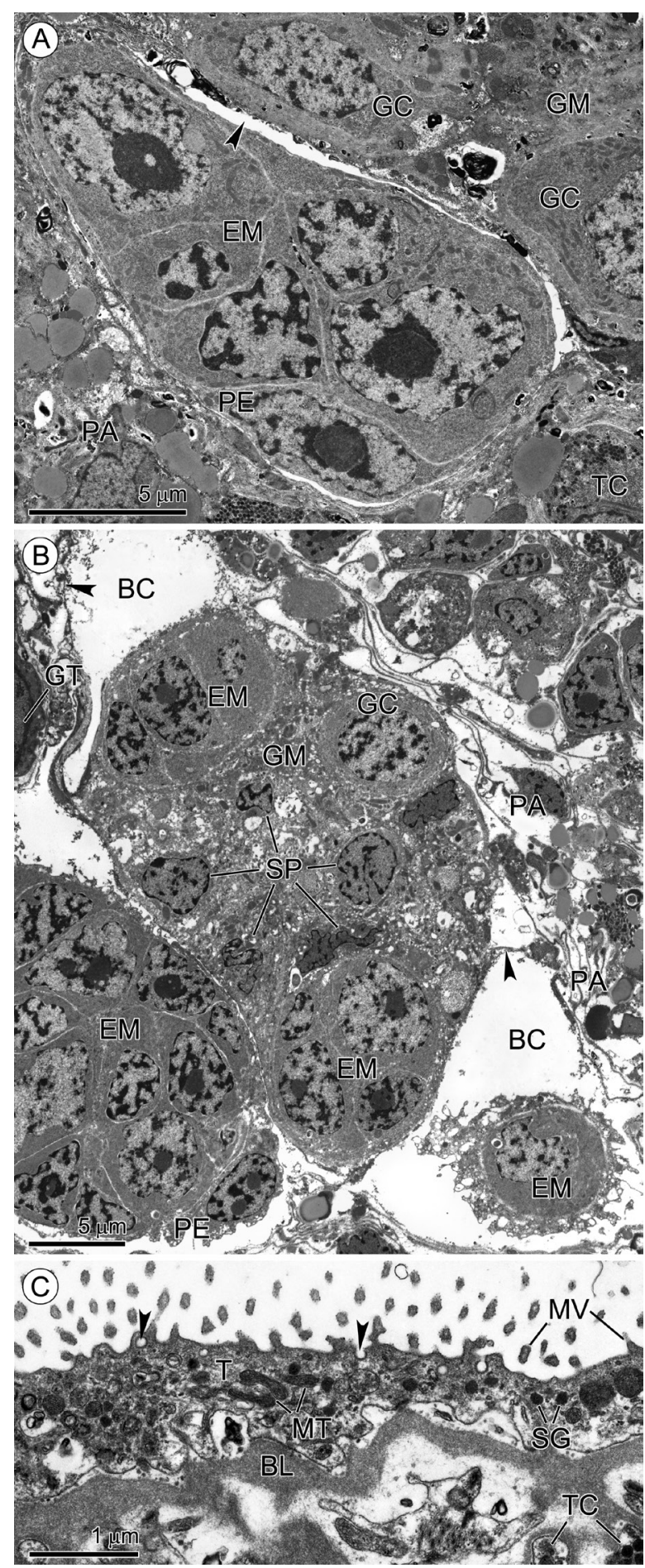

Fig. 3. Morphological features of small rediae of Himasthla elongata (Mehlis, 1831). A - micrograph of an early embryo separating (arrowhead) from the germinal mass; B - germinal mass protruding into the incipient body cavity. Note septa (arrowheads) separating the body cavity into sections and loose arrangement of surrounding parenchymal cells. $\mathbf{C}-$ micrograph of a redial tegument showing apical microvilli-like projections, mitochondria and secretory granules in tegumental cytoplasm. Arrowheads mark rounded microinvaginations of the apical plasma membrane and presumed pinocytotic vesicles. Abbreviations: BC - body cavity; BL - basal lamina; EM - early embryo; GC - germinal cell; GM - germinal mass; GT - gut; MT - mitochondria; MV - microvillus-like projections; PA - parenchymal cell; $\mathrm{PE}$ - primitive epithelium; SG - secretory granules; $\mathrm{SP}$ - supporting cell; $\mathrm{T}$ - tegument; $\mathrm{TC}$ - tegumental cell and its outgrowths.
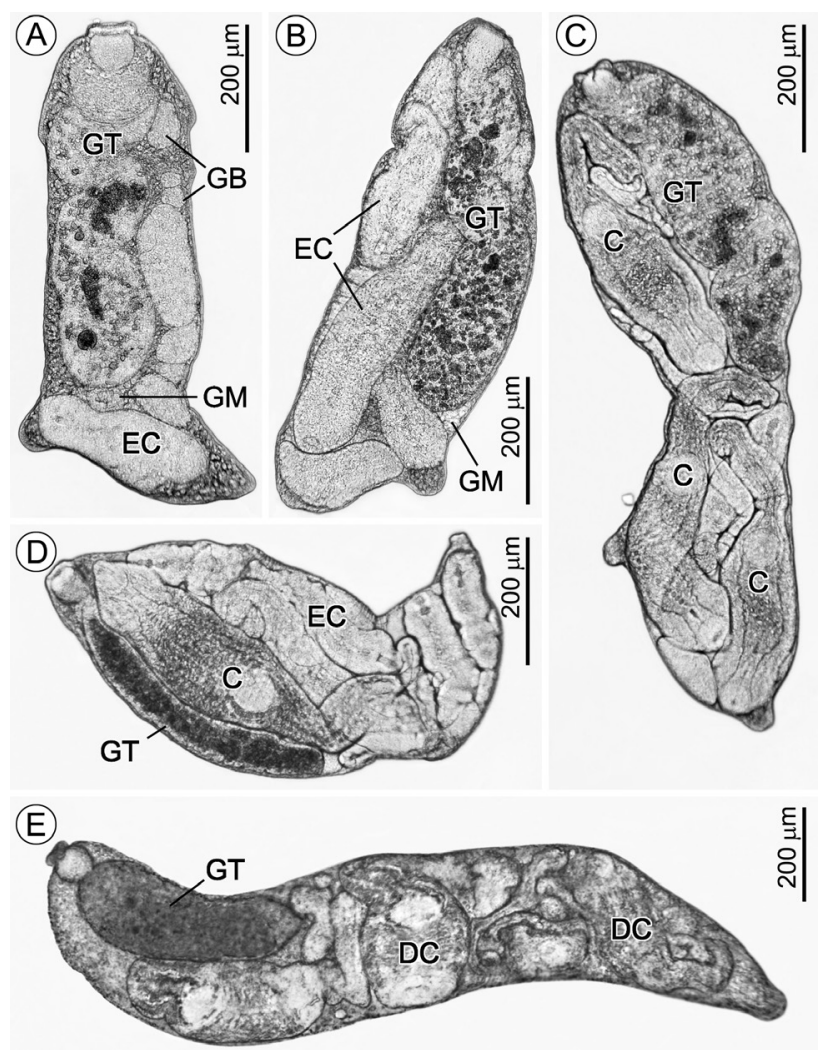

Fig. 4. Light microscopic images of living Himasthla elongata (Mehlis, 1831) rediae from Littorina littorea (Linnaeus). A, $\mathbf{B}$ - rediae with germinal balls and early embryonic cercariae in their body cavity; C - redia containing well developed motile cercariae; D - redia containing early embryonic cercariae and sporadic well developed immotile cercariae; $\mathbf{E}$ - redia at early stage of degeneration. Abbreviations: $\mathrm{C}$ - late embryonic cercariae; DC - degenerating cercariae; EC - early embryonic cercariae; GB - germinal balls; GM - germinal mass; GT - gut.

Gut does not reach the level of locomotory extensions, its length is $0.15-1.53 \mathrm{~mm}$.

(iv) Rediae with fully formed motile cercariae (RMC). Rediae morphologically identical to RC, $0.27-3.24 \mathrm{~mm} \times$ 0.14-0.9 mm, containing early cercarial embryos, late embryonic cercariae and fully formed motile cercariae in the body cavity (Fig. 4C). Gut length is $0.25-1.8 \mathrm{~mm}$.

(v) Rediae with redial embryos (RRE). Rediae morphologically identical to RC and RMC but containing, besides cercarial embryos at various stages of development, a few (1-2) small rediae of the next generation in their body cavity (Fig. 1A).

(vi) Degenerating rediae (DR) (Fig. 4E). Large, no longer reproducing rediae at various stages of degeneration.

All redial clonal groups examined were heterogeneous and contained rediae of all the above types except RRE. The latter were rare, their proportion in the clonal groups studied being $0.016 \%(0.002-0.056 \%)$. YR made up $22.6 \%$ (21.8-23.3\%), RCE - 10.9\% (10.4-11.5\%), RC - 29.9\% (29.1-30.7\%), RMC - 21.6\% (20.9-22.3\%), DR - 15.1\% (14.4-15.7\%). The ratio YR/RCE/RC/RMC/DR usually varied greatly across the clonal groups, being similar 


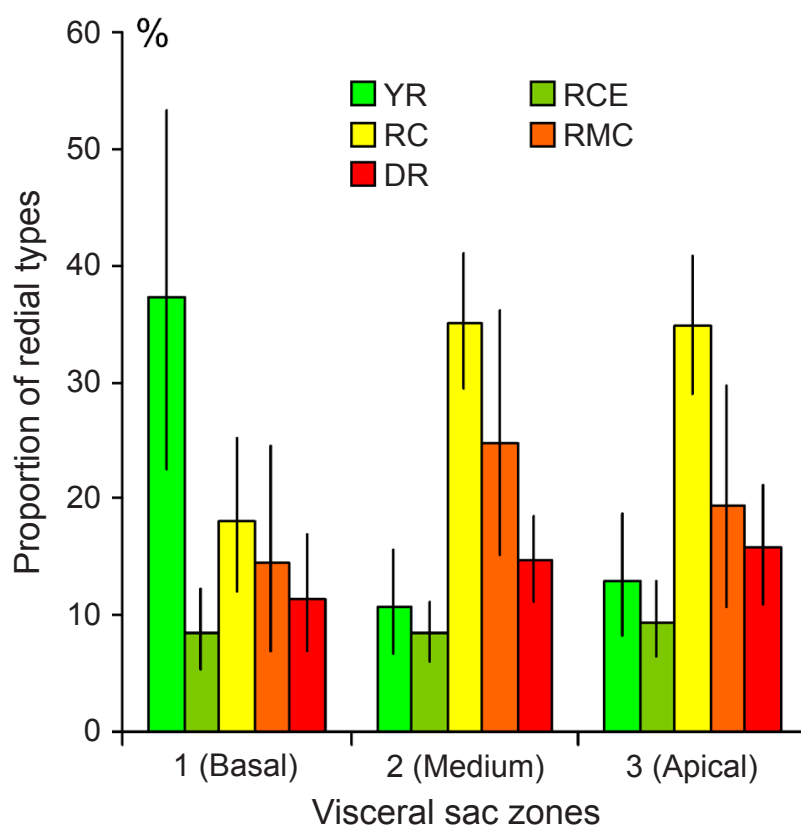

Fig. 5. Proportion of different types of rediae of Himasthla elongata (Mehlis, 1831) in different parts of visceral sac of the molluscan host Littorina littorea. Abbreviations: YR - small (young) rediae; RCE - rediae with early cercarial embryos; RC - rediae with late embryonic cercariae; RMC - rediae with fully formed motile cercariae; DR - degenerating rediae.

only in two out of the 18 clonal groups studied ( $\chi 2$-test, $\mathrm{P}>0.05)$.

Rediae populated the visceral sac non-uniformly: on the average, zone 1 contained 253 (199-314) rediae, zone 2 - 258 (198-333) and zone 3 - 151 (122-188). Fragments of the apical part of the visceral sac (zone 3 ) contained fewer rediae than fragments of the basal and middle part (zones 1 and 2), the difference being statistically significant (median test, $\mathrm{P}<0.01$ ). Fragments of different parts of the visceral sac also differed (ANOVA, $\mathrm{P}<0.01$, $\left.\eta^{2}=20.2 \%, P\left(\eta^{2}\right)<0.01\right)$ in the average relative volume occupied by rediae. The total relative volume of rediae in the examined fragments of zone 1 made up on the average 39.1 (25.7-54.4), of zone $2-61.3$ (48.2-75.6), and of zone $3-34.0$ (28.6-39.8). Zone 2 was the most densely populated by the parasites, the total volume of rediae in it exceeding that in zone 1 (ANOVA, $\mathrm{P}<0.05$ ) and in zone 3 (ANOVA, $\mathrm{P}<0.01$ ).

Different parts of the visceral sac also differed in the proportion of redial types (Fig. 5). Significant differences were revealed in the proportions of YR (ANOVA, $\mathrm{P}<0.01$, $\left.\eta^{2}=30.1 \%, \mathrm{P}\left(\eta^{2}\right)<0.01\right)$ and RC (ANOVA, $\mathrm{P}<0.01$, $\left.\eta^{2}=30.6 \%, P\left(\eta^{2}\right)<0.01\right)$. In the basal part of the visceral sac (zone 1) the proportion of YR was higher (difference statistically significant, Tukey Post-Hoc, $\mathrm{P}<0.05)$ and that of RC lower (Tukey Post-Hoc, $\mathrm{P}<0.01$ ) than in the middle (zone 2) and the apical part (zone 3). There were no statistically significant differences in the proportions of RCE and DR in different parts of the visceral sac. RRE were found sporadically. We did not find any rediae of $H$. elongata in the mantle, the anterior complex of organs (head, ctenidium) and the foot of L. littorea.

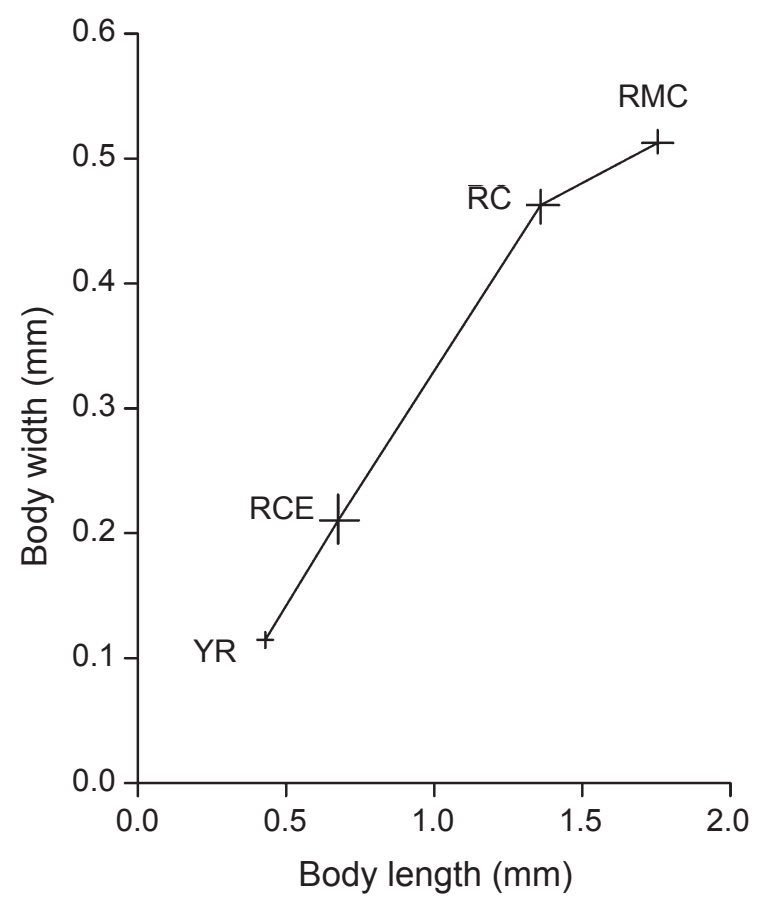

Fig. 6. Average linear size of the different types of rediae of Himasthla elongata (Mehlis, 1831). Abbreviations: YR - small (young) rediae; RCE - rediae with early cercarial embryos; $\mathrm{RC}$ - rediae with late embryonic cercariae; $\mathrm{RMC}$ - rediae with fully formed motile cercariae.

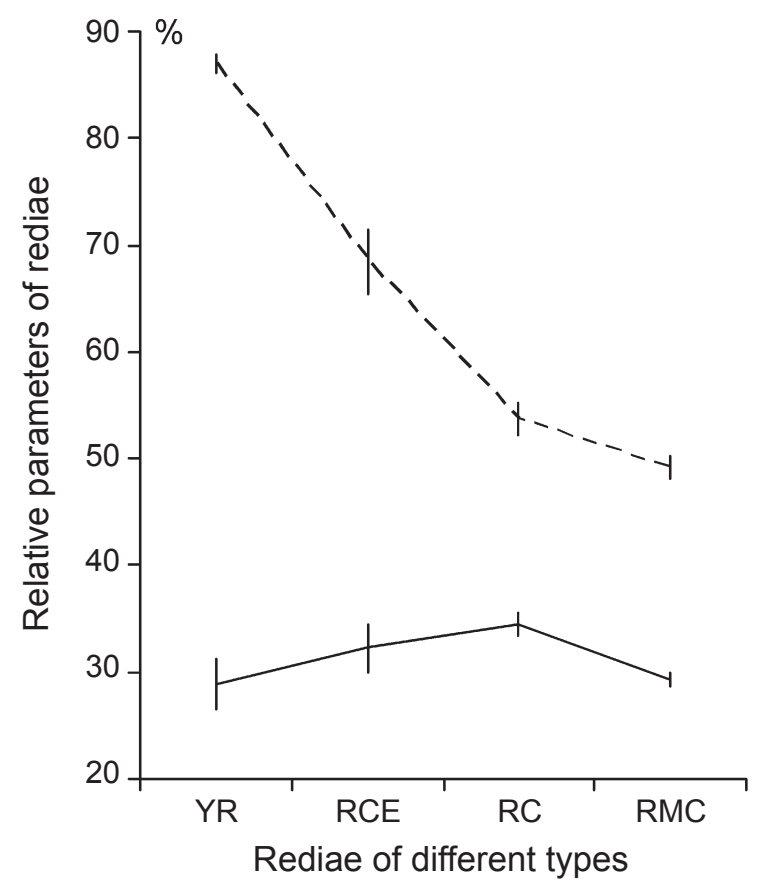

Fig. 7. Relative width (width to length ratio in \%; broken line) and relative gut length (gut length to body length ratio in \%; continuous line) of different types of rediae of Himasthla elongata (Mehlis, 1831). Abbreviations: YR - small (young) rediae; $\mathrm{RCE}$ - rediae with early cercarial embryos; $\mathrm{RC}$ - rediae with late embryonic cercariae; RMC - rediae with fully formed motile cercariae. 

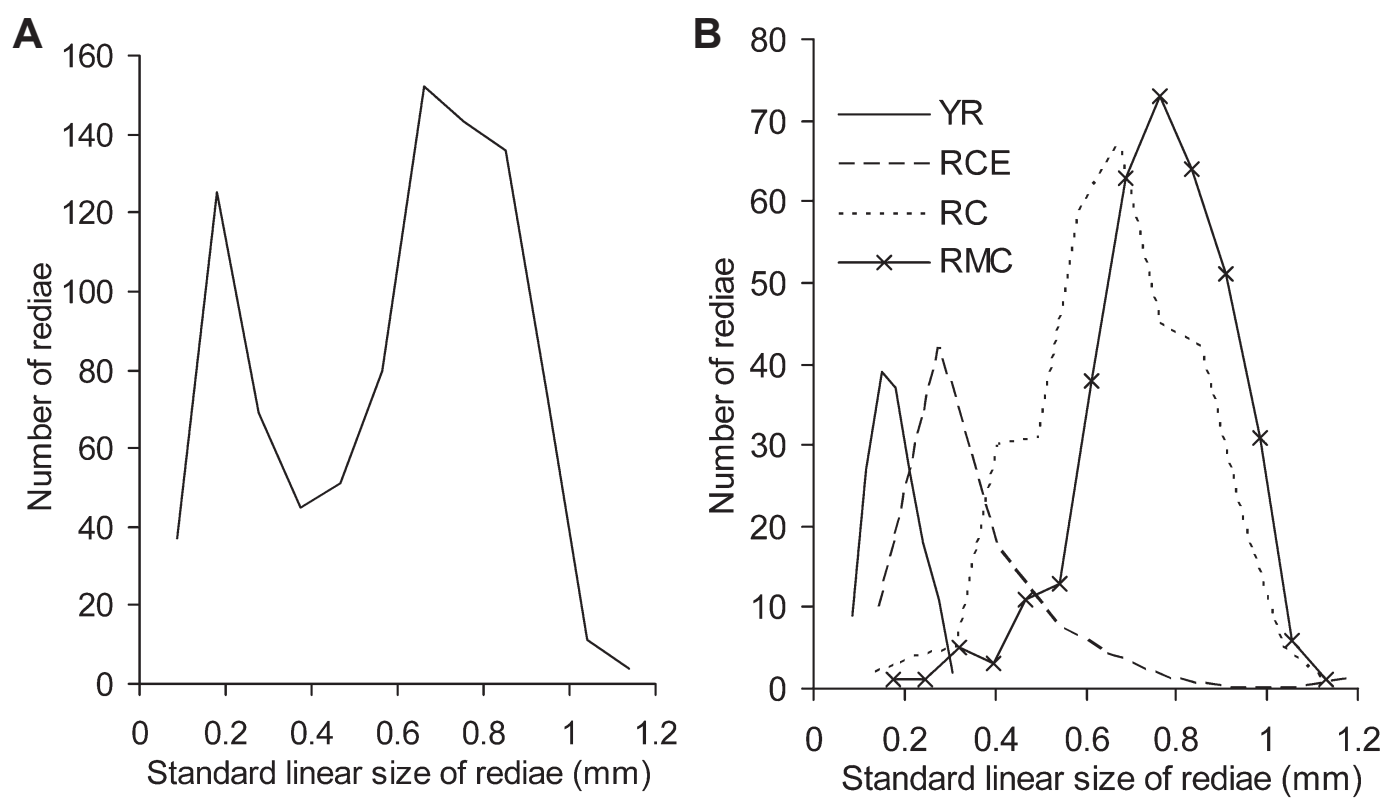

Fig. 8. Size-frequency distribution of standard linear size in rediae of Himasthla elongata (Mehlis, 1831). A - all rediae pooled; B - different types of rediae. Abbreviations: YR - small (young) rediae; RCE - rediae with early cercarial embryos; RC - rediae with late embryonic cercariae; RMC - rediae with fully formed motile cercariae.
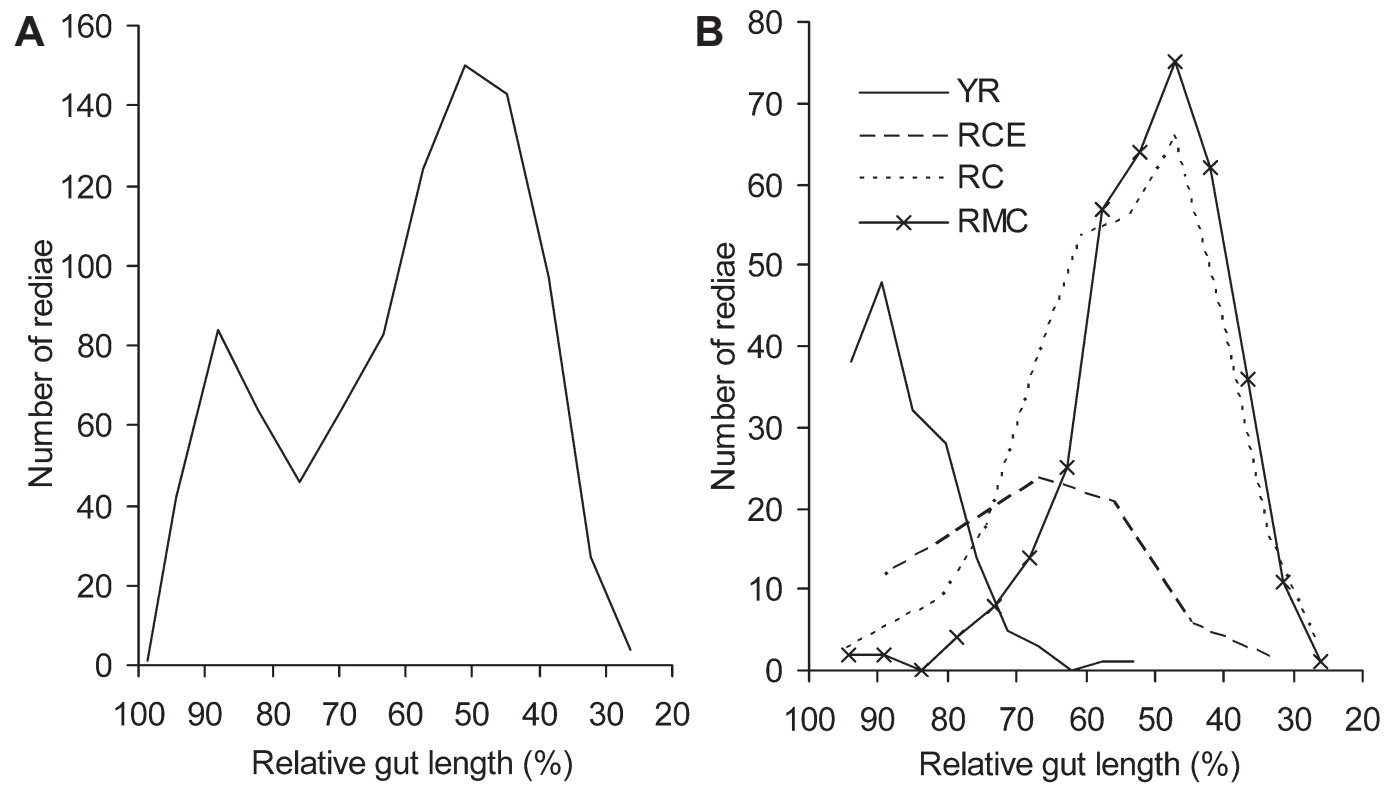

Fig. 9. Distribution of relative gut length (gut length to body length ratio in \%) in rediae of Himasthla elongata (Mehlis, 1831). A - all rediae pooled; B - different types of rediae. Abbreviations: YR - small (young) rediae; RCE - rediae with early cercarial embryos; $\mathrm{RC}$ - rediae with late embryonic cercariae; RMC - rediae with fully formed motile cercariae.

Natural mortality of the snails kept in the subtidal nets was low, $5-7 \%$ a year. In control surveys all the survivors shed cercariae, indicating that the clonal group was functioning for at least 5 years (2010-2014).

\section{Features of redial growth and size-frequency distribution of different redial types in the clonal group}

Our analysis of the redial growth focussed on four major types of rediae - YR, RCE, RC and RMC. Together, they made up $c a 85 \%$ of all clonal groups. RRE, which were very rare, and DR, which no longer participated in reproduction, were left out of the analysis.

The linear size of the rediae increased sequentially in YR, RCE, RC and RMC redial types (median test, $\mathrm{P}<0.01$ ) (Fig. 6). The growth was close to isometric from YR to RCE and further to RC but slowed down at the transition from RC to RMC. The relative width (width to length ratio) of the rediae varied from $4.7 \%$ to $87.1 \%$ (mean $31.9 \pm 0.7 \%$ ). The distribution of the relative body width was unimodal with a slight positive skew $(A s=0.46)$. Rediae of different types differed only slightly in the rela- 
tive body width (Fig. 7). Only the fully mature individuals (RMC) had a relatively smaller body width than RCE and $\mathrm{RC}$ (median test, $\mathrm{P}<0.01)$, the other differences not being statistically significant (Fig. 7).

SLS of rediae varied from 0.08 to $1.60(0.59 \pm 0.02)$. The distribution of SLS of rediae was bimodal, the modal classes corresponding to individuals with the SLS 0.18 $\pm 0.1 \mathrm{~mm}$ and $0.66 \pm 0.1 \mathrm{~mm}$ (Fig. 8A). Distributions of the rediae of the four types under analysis were unimodal and had different skews (Fig. 8B). Skewness of the size-frequency distributions of different types (YR, RCE, $\mathrm{RC}, \mathrm{RMC}$ ) was as follows: $A s_{\mathrm{YR}}=0.44 ; A s_{\mathrm{RCE}}=1.96$; $A s_{\mathrm{RC}}=-0.1 ; A s_{\mathrm{RMC}}=-0.72$.

Gut length increased sequentially in YR, RCE, $\mathrm{RC}$ and $\mathrm{RMC}$ redial types, measuring on the average $0.68 \pm 0.02 \mathrm{~mm}$. Relative gut length varied from $26.2 \%$ to $98.8 \%$ of body length $(57.5 \pm 1.0 \%)$. The distribution of the relative gut length was bimodal, the modal classes corresponding to individuals with gut length comprising on average $51.0 \pm 6.2 \%$ and $88.3 \pm 6.2 \%$ of body length (Fig. 9A). The relative gut length decreased from YR to RMC (median test, $\mathrm{P}<0.01$ ) (Fig. 7). All redial types (YR, $\mathrm{RCE}, \mathrm{RC}, \mathrm{RMC}$ ) significantly (median test, $\mathrm{P}<0.01$ ) differed by the values of this parameter (Fig. 7). Distributions of relative gut length were unimodal for any rediae type (Fig. 9B). Skewness of distributions of this parameter for different types (YR, RCE, RC, RMC) was as follows: $A s_{\mathrm{YR}}=-1.25 ; A s_{\mathrm{RCE}}=-0.24 ; A s_{\mathrm{RC}}=0.54 ; A s_{\mathrm{RMC}}=0.87$.

\section{DISCUSSION}

Our research provided some important information concerning the applicability of the eusociality concept to clonal redial groups in the molluscan host. Below we compare the precepts of the eusociality concept with the traditional views on self-sustaining infrapopulations (SSI) of rediae in the light of the newly obtained results.

\section{Morphological features of rediae of Himasthla elongata}

The alleged inability of 'soldier rediae' to reproduce is seen as an argument in favour of the eusocial organisation of redial groups (Hechinger et al. 2011). However, all the examined small rediae (YR) of $H$. elongata, which lacked an incipient brood chamber and thus corresponded to the 'soldier caste', possessed the reproductive organ - the germinal mass. It did not show any signs of degeneration and usually contained normal early embryos of the next generation. Germinal mass composition, the number of embryos, their location (in the germinal mass, in the cell mass at the posterior body end, or in the incipient body cavity) and the degree of body cavity development in different YR individuals varied, indicating that these structures were undergoing development.

The following scenario of early stages of redial postembryonic development may be suggested. In newborn rediae the parenchyma-surrounded germinal mass does not contain any embryos. As some of the germinal cells reach maturity, they cleave to form early embryos. The first germinal balls separate from the germinal mass and find themselves in the midst of the cells composing the YR posterior body end. As soon as there are 2 or 3 such embryos, a body cavity starts to form around them. In YR, only the initial stage of body cavity development, accompanied by loosening of the cell mass at the posterior body end, may be observed.

Thus, our results indicate that the reproductive process starts in small rediae of $H$. elongata. In our opinion, the same is likely to be the case in morphologically similar 'soldier' rediae (secondary rediae) of Himasthla sp. B described by Hechinger et al. (2011). Although these authors suggest that the 'soldiers' are incapable of reproduction, in their figures these rediae (referred to as 'attackers') can be clearly seen to contain embryos (see Hechinger et al. 2011; fig. 4c,e, p. 661). A poorly detectable germinal mass has been noted in small (= young) rediae of Echinostoma spiniferum (La Valette, 1855) sensu Našincová (1992) corresponding to 'soldiers' (Zikmundová 2011). Germinal mass has been found by Ataev and Dobrovolskij (1990) in all young rediae of different generations of Philophthalmus rhionica Tihomirov, 1976 - a species of the same genus as Philophthalmus sp., for which non-reproductive mini-rediae and reproductive individuals in clonal groups have been described (Leung and Poulin 2011, Lloyd and Poulin 2012).

According to the eusocial concept, the main function of the rediae belonging to the 'reproductive caste' is reproduction. If so, one may expect them to have a well-developed and functionally active germinal mass. However, this is not the case in the large rediae of $H$. elongata (RC, RMC), morphologically corresponding to the 'reproductive caste'. These rediae frequently have no germinal mass at all. The fact that germinal balls are seldom found in their body cavity also indicates the decline of the reproductive function.

Our observations, while contradicting the eusocial concept (Hechinger et al. 2011, Leung and Poulin 2011, Miura 2012), are in good agreement with the light microscopic data of Ataev et al. (2007) and Isakova (2011) on the dynamics of functional activity of the germinal mass in the rediae of the Echinostomatidae and Psilostomidae. According to these authors, in large rediae packed with embryonic cercariae ('mature' rediae) of Psilotrema tuberculate Filippi, 1857, Sphaeridiotrema globulus (Rudolphi, 1814) (Psilostomidae) and Echinostoma caproni Richard, 1964 (Echinostomatidae), the germinal mass is either degenerating or absent. These rediae are, in fact, nothing more than brood chambers.

In $H$. elongata, reproduction is most intense in middle-sized rediae corresponding to RCE (Fig. 4A,B) (Podvyaznaya and Galaktionov 2014). They have an actively functioning germinal mass, in which new germinal cells are formed and embryos develop from them at the same time.

\section{Developmental features of the rediae of H.elongata}

The analysis of the germinal elements in different types of rediae of $H$. elongata clearly points to a conclusion that there are no specialised castes of non-reproductive and reproductive rediae. All of the redial types described in our study represent different stages of redial development. 
The earliest stage is the small rediae, in which germinal mass and brood chamber differentiate to become functionally committed. At the next stage (RCE) the germinal mass is activated and the body cavity enlarges dramatically, ready to house newly formed embryos. This expansion of the body cavity accounts for much of the total growth of redial size. The development of the body cavity in the posterior part, including the locomotory extensions, results in a gradual displacement of the end of the gut and the nearby germinal mass into the middle body part. Various specialised cells, which in small early rediae densely fill the solid posterior part and the locomotory extensions, are distributed into a fine layer below the covering epithelium to form the redial body wall. The entire length of the body cavity fills with embryos, which continue to grow and differentiate. Formation of new embryos in the germinal mass seems to slow down after the first fully-formed motile cercariae appear in the redial body cavity. By the time most embryos reach this developmental stage (RMC), the germinal mass no longer functions and its residues disappear. When most embryos develop into cercariae, the redia degenerates.

\section{Size-frequency distribution of individuals in redial clonal groups of $\boldsymbol{H}$. elongata}

Another argument in favour of the existence of non-reproductive and reproductive castes in redial 'colonies' is the bimodal distribution of their size parameters (Hechinger et al. 2011, Leung and Poulin 2011, Miura 2012). In our study the distribution of the rediae of $H$. elongata (Fig. 8A) in relation to size and gut to body length ratio (Fig. 9A) was also bimodal when all functional redial types were pooled. A more detailed analysis showed, however, that the observed bimodal size-frequency distribution (SFD) (Figs. 8A, 9A) is the sum of unimodal SFD of rediae at various maturity stages (Figs. 8B, 9B). Furthermore, the first modal class, which should correspond to the non-reproductive 'soldiers', was considerably contributed to by RCE. The modal class of rediae with the greatest relative gut length also contained reproductive individuals (Fig. 9B). Thus, the first modal class of the SFD rediae of $H$. elongata does not correspond to non-reproductive 'soldiers'. A considerable overlap between SFD of rediae at different stages of maturity (Figs. 8B, 9B) also testifies against the division of rediae into two castes.

The proponents of the ideas about eusociality in trematodes (Hechinger et al. 2011, Leung and Poulin 2011, Miura 2012) admitted that the 'soldiers' may eventually contribute to reproduction by maturing into cercariae producers. At the same time these authors found very few intermediate morphs between non-reproductive and reproductive rediae, concluding that there were two distinct redial morphs (= castes) in the colony (Hechinger et al. 2011, Miura 2012). In our study, however, such intermediate morphs, represented by RCE, were present in all clonal groups although they were indeed less numerous than the others. Intermediate morphs were also found in clonal groups of rediae of Echinostoma spiniferum (see Zikmundová 2011).
In our opinion, the bimodal SFD in rediae is formed under the influence of their growth features (i) and the developmental arrest in young rediae (ii).

(i) Redial growth in H. elongata

Young rediae (YR and RCE at the least advanced stage of development), similarly to all parenchymatous organisms, grow by proliferation, i.e. increase in the number of cells. However, as soon as a brood chamber appears, further growth of the redia is also associated with the expansion of this cavity and mainly proceeds by the extension ('growth by extension'). The size of an organism growing by extension is likely to increase much faster than that of an entirely parenchymatous organism. If so, we may expect bimodal distribution of rediae as to their morphometric characters (the first mode characterises the distribution of small parenchymatous organisms and the second one, that of larger individuals with a brood chamber), and a considerable positive skewness for the morphometric characters of the immature stages with a developing brood chamber.

At the same time, we should expect the distribution of mature rediae to be negatively skewed because some of them may not have enough room for growth and the attainment of the maximum possible size. Indeed, such was the distribution of size parameters of the rediae in $H$. elongata clonal groups (Fig. 8B). The distribution of immature rediae (YR and RCE) had a right skew $(A s>0)$, and that of the mature ones (RC and RMC), a left skew $(A s<1)$. The greatest right skew of the size distribution was observed in $\operatorname{RCE}\left(A s_{\mathrm{RCE}}=1.96\right)$. It is in these rediae that an active development of the body cavity starts, i.e. they begin to grow 'by extension'.

Intermediate morphs such as RCE may be short-lived at relatively high temperatures, which accelerate redial development. California and Japan, where studies by Hechinger et al. (2011) and Miura (2012), respectively, were made, enjoy a much warmer climate than the White Sea. This may be the reason why these authors revealed a distinct bimodality in the size-frequency distributions of rediae in clonal groups. Incidentally, non-reproductive secondary morphs ('soldiers') in the study by Hechinger et al. (2011) also included some RCE (see above). Furthermore, DR macerate and disintegrate rapidly at high temperatures and so might have been overlooked in the study by Hechinger et al. (2011).

Redial size increased almost isometrically until fully formed motile cercariae appeared in the brood chamber and were then released (Figs. 6, 7). This could be expected, taking into account the nature of redial growth (see above). Gut length increased throughout the lifespan of the rediae of $H$. elongata but did so more slowly than body length (Fig. 7). Thus, the size of redial body increased at the expense of the increasing volume of germinal elements and maturing cercariae in the body cavity, i.e. by means of 'growth by extension'. As rediae matured, the character of the change of relative morphometric parameters changed at the transition point from RC to RMC: both the increase in body length relative to gut length and the redial growth in width slowed down at the same time (Fig. 7). These chang- 
es are explained by the beginning of cercariae emission on the one hand and, on the other hand, by the fact that new embryos no longer enter the body cavity because the potential of the germinal mass has expired. The rediae 'collapse'.

(ii) Developmental arrest in rediae of H.elongata and sustainability of their clonal groups

The development of YR may be arrested, as indicated by their considerable pool in periwinkles. This pool is probably formed quite early, when the first redial generations, busy to occupy the host as soon as possible, produce not only cercarial embryos but also numerous embryos of the next redial generation. Redial/sporocyst clonal groups are formed in this way in different trematode species (e.g. Kechemir and Théron 1980, Théron 1981, Touassem and Théron 1986, Ataev and Dobrovolskij 1990), including echinostomes (Ataev et al. 2005, 2006). When the numbers of a clonal group reach a certain threshold, various density-dependent factors come into play. The production of rediae by rediae is arrested or slowed down and so is the development of newborn YR. Otherwise, an unconstrained increase in numbers of rediae might kill the host. Later, as old individuals die, the clonal group is recruited from the YR pool. Rediae probably leave the state of developmental arrest following specific chemical cues. This might explain the failure to grow reproductives from 'soldiers' in culture (Lloyd and Poulin 2013).

YR pool seems to be supplemented throughout the lifetime of the clonal group in the molluscan host by rediae giving birth to other rediae. Although in our study RRE were very rare, their share in the clonal group was probably underestimated considerably. This is due to the fact that early redial embryos and cercarial embryos inside the mother organism are indistinguishable during in vivo microscopic examination. Only late embryonic rediae of the next generation with a well-developed gut, which roughly correspond to YR, can be identified with certainty.

\section{Behavioural differences between small and large rediae and the character of redial feeding}

Behavioural differences between small rediae ('soldiers') and large rediae ('reproductives') are another argument in favour of the eusociality concept. Small rediae crawl vigorously and attack parthenitae of other species (or conspecifics from other colonies) in the mollusc as well as in culture. Large reproductives are considerably less active. They do not attack hetero- or conspecifics or do so much more rarely and slowly (Hechinger et al. 2011, Leung and Poulin 2011, Nielsen et al. 2014).

It is well known that rediae can attack parthenitae of other species (see Lie 1967, 1973, Lim and Heyneman 1972, Combes 1982). Both young small rediae and older large ones were shown to do that (Lie 1969). For histophagous rediae, the parthenitae of other trematode species (and sometimes also conspecifics) are just as good food as molluscan host tissues (see, e.g. Lie 1969, Gorbushin and Shaposhnikova 2002). In fact, the parthenitae may even be preferable because they accumulate a considerable amount of nutrients. In an experimental study of Gorbushin and Shaposhnikova (2002), rediae of $H$. elongata survived in axenic culture for more than five months solely on dead rediae and cercariae.

Feeding on dead conspecifics seems to be common in rediae. Young rediae of Paramonostomum alveatum (Mehlis, 1846) (Notocotylidae) in the White Sea snails Hydrobia ventrosa (Montagu) readily consumed dying and dead mother and daughter rediae (K.V.G. - unpubl. data). On the one hand, such dead parthenitae as well as dead cercariae are an easily accessible source of energy-rich food. On the other hand, in this way rediae clean the mollusc from the toxic substances formed during maceration of the dead remains. This cleaning decreases the parasitic impact on the molluscan host, promoting long-term survival of the clonal group.

Different frequencies of attacks by small and large rediae observed in Himasthla sp. B and some other trematode species (Hechinger et al. 2011, Leung and Poulin 2011, Miura 2012) may be associated with age-related changes in the character of redial feeding. Rediae may feed not only using their digestive tract but also absorbing nutrients via the tegument. The relative importance of these two feeding modes may differ across species, generations and maturity stages (for review see Galaktionov and Dobrovolskij 2003). Large rediae (RC, RMC) have a much greater body surface area than small ones (YR, early RCE), whereas an increase in the gut length is not so dramatic (Fig. 7).

The ultrastructure of the covering epithelium seemed to be the same in different types of rediae of H. elongata, being also similar to that of the 'transport epithelium' in the rediae of Himasthla quissetensis (Miller et Northup, 1926) (see Hoskin 1975). However, the relative importance of the covers for nutrient absorption is likely to increase with the increasing surface area. This, as well as the loss of motility by large rediae, whose body cavity fills with numerous motile cercariae, results in a change in their feeding behaviour: active foraging including predation loses importance.

After this paper has already been prepared for submission, the study by Mouritsen and Halvorsen (2015) was published. These authors showed that in in vitro experiments 'non-reproductive' minor rediae of $H$. elongata attacked sporocysts of Renicola roscovita (Stunkard, 1932) more often than similarly-sized pieces of the molluscan-host digestive gland. At the same time, large 'reproductive' rediae attacked both sporocysts and host tissue much more rarely than minor 'non-reproductive'. Mouritsen and Halvorsen (2015) interpret these findings as unequivocal evidence that minor rediae of $H$. elongata are adapted for the defence of clonal redial 'colony'.

This interpretation, however, does not look convincing in the light of the age-related changes in the feeding behaviour of the rediae of $H$. elongata discussed above. Furthermore, more frequent attacks of minor rediae on sporocysts in in vitro experiments may also be explained by the experimental design. When the digestive gland is cut into pieces, its cells, inevitably damaged in the process, release proteolytic enzymes they are rich in. When these pieces were placed in water, a zone of high concentration of proteolytic enzymes was formed around them. These enzymes, being toxic for the rediae, were likely to repel them and the num- 
ber of attacks on the sporocysts, which lacked the 'halo' of proteolytic enzymes, might have increased as a result. According to our observations, small rediae of $H$. elongata concentrate in the kidney of $L$. littorea, where they readily feed on its loose tissues lacking in proteolytic enzymes (K.E.N. - unpubl. data).

\section{Distribution of rediae of $\boldsymbol{H}$. elongata within the host and the 'colony' defence against invaders}

According to the eusociality concept, small rediae ('soldiers') concentrate in the anterior parts of the molluscan host (the so-called 'invasion fronts') in order to protect the 'colony' from invaders, the miracidia of other trematode species (Hechinger et al. 2011). However, only free-swimming miracidia penetrate the mollusc via its anterior parts (usually the mantle). Many if not most trematode species infect the mollusc passively, with infective eggs (see for review Galaktionov and Dobrovolskij 2003). Miracidia hatch in the host gut and penetrate its walls in various areas of the visceral sac (zones 2 and 3 in our study). This is where the 'invasion fronts' are actually located. If so, the 'soldiers' concentrated in the anterior body part protect the 'colony' only from species with free-swimming miracidia. This seems unlikely, to say the least.

An uneven distribution of small rediae may be alternatively explained by the niche segregation between young and mature individuals. This may be in part associated with the age-related differences in their feeding preferences (see above) and in part, with avoidance of competition with larger individuals (Gorbushin and Borisova 2014). In a detailed study of formation of clonal redial groups of Echinostoma caproni in Biomphalaria spp., newborn rediae attempted to leave the zone where mature rediae concentrated at any stage of functioning of a clonal group (Ataev et al. 2005). Young individuals migrate across the molluscan body along large blood vessels or are passively carried by the hemolymph currents into the sinuses of the anterior part of the body. These migrations have also been described in some other echinostomes (Ataev et al. 2005). As they develop, young rediae of $H$. elongata move from the anterior parts of the molluscan host towards the gonads and hepatopancreas (zones 2 and 3) where they find optimal feeding conditions. It is in these areas that RC concentration was the highest. Apparently, collapsed RMC can be passively carried with the hemolymph to other parts of mollusc and so can DR, which were almost evenly distributed across the three studied fragments of the visceral sac (Fig. 5).

In the newly published article of Mouritsen and Halvorsen (2015), the defence role of 'non-reproductive' rediae is additionally supported by the results of field research: H. elongata-Renicola roscovita double infection of $L$. littorea in the studied area (coastal waters of Knebel Vig, Denmark) was much less frequent than expected by chance. However, this discrepancy may be explained by the differences in the impact of the parthenitae of these species on the molluscan host. Sporocysts of $R$. roscovita cause atrophy of most of the digestive gland of the molluscan host, whereas the pathogenic effect of the rediae of $H$. elongata is not so pronounced (Gorbushin 2000). As a result, the molluscs infected with $R$. roscovita have a shorter lifespan than those infected with $H$. elongata.

Our observations at the White Sea show that overwintered Littorina saxatilis (Olivi) infected with mature groups of sporocysts of Cercaria parvicaudata Stunkard et Shaw, 1931 (a species related to Renicola spp., possibly, a synonym of $R$. roscovita) die early in summer. At the same time, the lifespan of the redial clonal groups of $H$. elongata in L. littorea is at least 5 years. Therefore, periwinkles with a double infection (Himasthla spp.-Renicola spp.) are likely to be eliminated quite fast. In this way, infection with $H$. elongata would accumulate in the molluscan population.

Finally, experiments of Gorbushin and Borisova (2014) on transplantation of rediae of $H$. elongata to L. littorea infected with parthenitae of Renicola roscovita and Cryptocotyle lingua (Creplin, 1825) and uninfected snails showed that immune reactions of $L$. littorea effectively defend the already established clonal group of parthenitae from other heterospecific invaders. Thus, the maintenance of a specialised non-reproductive 'soldier caste' is ineffective in terms of evolution and the application of the eusocial concept at least to the redial clonal groups of $H$. elongata seems equivocal (Gorbushin and Borisova 2014).

Clonal groups of rediae of $H$. elongata in the snail L. littorea examined in our study were undoubtedly self-sustaining infrapopulations. They always contained a constantly renewed pool of YR, from which new cercariae-producing rediae were recruited to substitute 'worn-out' degenerating individuals. The germinal mass in rediae with fully formed cercariae degenerated and numerous degenerated rediae were present in the molluscan host. Last but not least, the clonal group existed in the molluscan host for many years, its lifetime being probably comparable with that of the snail itself. All these considerations indicate the self-sustaining nature of the clonal groups, leaving no possibility for any other interpretation. The arguments in favour of the colonial nature of rediae groups in the molluscan host can be easily explained by the ontogenetic changes in redial physiology and behaviour, the demographical process in their groups and the immune response of the molluscan host.

In our opinion, the proponents of the 'eusocial concept' fail to take into account the necessity of a constant turnover in redial clonal groups. Otherwise, they would perish as soon as the relatively small reproductive potential of individual rediae is exhausted. The nature of this turnover is species-specific (see Introduction) and may be determined both by host-related factors (such as the physiological state and size) and environmental ones (such as the temperature). This explains the differences in the proportion of different redial types in snails of approximately the same size (this study) and in snails of different sizes (Leung and Poulin 2011, Zikmundová 2011, Nielsen et al. 2014) collected in localities (Nielsen et al. 2014) and geographical regions (Lloyd and Poulin 2014) with differing environmental parameters.

To sum up, the arguments in favour of the eusocial organisation in clonal groups of trematode rediae, with di- 
vision of labour between soldier and reproductive castes, are unconvincing. A classical approach considering these groups as self-sustaining infrapopulations is much more justified. Finally, we would like to note that, while disagreeing with the eusociality concept, we find the recent surge of interest in trematode parthenitae very satisfactory. These life cycle stages, with their extremely high reproductive potential, are an important, if not the crucial component of the digenean success. A profound analysis of parthenitae and their clonal groups in the first intermediate host is essential for understanding trematode transmission and evolutionary trends of this parasitic flatworm group.

Acknowledgements. We thank Natalia Lentsman for her help with the translation of the MS into English. We are grateful to the anonymous reviewers for valuable comments on an earlier draft of the manuscript. This study was funded by the Russian Foundation for Basic Research (grant no. 13-04-00875) and the research programme of the Zoological Institute of the Russian Academy of Sciences (project no. 01201351191).

\section{REFERENCES}

Ataev G.L. 1991: [Temperature influence on the development and biology of rediae and cercariae of Philophthalmus rhionica (Trematoda).] Parazitologyia 25: 349-359. (In Russian.)

Ataev G.L., DobrovolskiJ A.A. 1990: [Development of microhemipopulation of parthenitae of the trematode Philophthalmus rhionica.] Parazitologiya 24: 499-508. (In Russian.)

Ataev G.L., DobrovolskiJ A.A., Isakova N.P. 2005: [The formation of parthenitae infrapopulation of Echinostoma caproni (Digenea: Echinostomatidae).] Parazitologiya 39: 124-136. (In Russian.)

Ataev G.L., Dobrovolskij A.A., Isakova N.P. 2006: [Development of mother sporocysts of Echinostoma caproni (Trematoda: Echinostomatidae).] Parazitologiya 40: 47-56. (In Russian.)

Ataev G.L., Isakova N.P., DobrovolskiJ A.A. 2007: [Reproduction of the trematode Echinostoma caproni parthenitae (Digenea: Echinostomatidae).] Parazitologiya 41: 512-525. (In Russian.)

Belfaiza M., Rondelaud D., Moncef M., Dreyfuss G. 2004: Fasciola hepatica: cercarial productivity of redial generations in long-surviving snails. J. Helminthol. 78: 115-120.

Combes C. 1982: Trematodes: antagonism between species and sterilizing effects on snails in biological control. Parasitology 84: 151-175.

Cribb T.H., Adlard R.D., Hayward C.J., Bott N.J, Ellis D., Evans D., Nowak B.F. 2011: The life cycle of Cardicola forsteri (Trematoda: Aporocotylidae), a pathogen of ranched southern bluefin tuna, Thunnus maccoyi. Int. J. Parasitol. 41: 861-870.

Dinnik J.A., Dinnik N.N. 1963: Effect of the seasonal variations of temperature on the development of Fasciola gigantica in the snail host in the Kenya Highlands. Bull. Epiz. Dis. Afr. 11: 197-207.

Dinnik J.A., Dinnik N.N. 1964: The influence of temperature on the succession of rediae and cercariae generations of Fasciola gigantica in a snail host. Parasitology 54: 59-65.

Dobrovolskij A.A., Ataev G.L. 2003: The nature of reproduction of Digenea rediae and sporocysts. In: C. Combes and J. Jourdane (Eds.), Hommage à Louis Euzet - Taxonomy, Ecology, and Evolution of Metazoan Parasites. Presses Universitaires de Perpignan, Perpignan, pp. 249-272.

DöNGES J. 1971: The potential number of redial generations in echinostomatids (Trematoda). Int. J. Parasitol. 1: 51-59

Dönges J., Gotzelmann M. 1988: Digenetic trematodes: multiplication of the intramolluscan stages in some species is potentially unlimited. J. Parasitol. 74: 885-888.

Galaktionov K.V., Dobrovolskij A.A. 2003: The Biology and Evolution of Trematodes. Kluwer Academic Publishers, Boston, $592 \mathrm{pp}$.

Galaktionov K.V., Dobrovolskij A.A., Podvyaznaya I.M. 2014: [Evolution of morpho-functional organization of trematode parthenogenetic generations.] Zoologicheskii Zhurnal 93: 426-442. (In Russian.)

Ginetsinskaya T.A. 1954: [Life cycle and biology of the developmental stages of Cyclocoelum microstomum (Trematoda).] Uchenye Zapiski Leningradskogo Universiteta, Ser. Biol. 172: 90-112. (In Russian.)
Gorbushin A.M. 2000: [Comparative morphological-functional analysis of the gastropod-trematode interactions.] Parazitologiya 34: 502-514. (In Russian.)

Gorbushin A.M., Borisova E.A. 2014: Himasthla elongata: implantation of rediae to the specific iteroparous long-living host, Littorina littorea, results in the immune rejection. Fish Shellfish Immun. 39: 432-438.

Gorbushin A.M., Shaposhnikova T.G. 2002: In vitro culture of the avian echinostome Himasthla elongata: from redia to marita. Exp. Parasitol. 101: 234-239.

Gunn A., Pitt S.J. 2012: Parasitology: An Integrated Approach. Wiley-Blackwell, New Delhi, 442 pp.

Hechinger R.F., Wood A.C., Kuris A.M. 2011: Social organization in a flatworm: trematode parasites form soldier and reproductive castes. Proc. R. Soc. B, Biol. Sci. 278: 656-665.

Hoskin G.P. 1975: Light and electron microscopy of the host-parasite interface and histopathology of Nassarius obsoletus infected with rediae of Himasthla quissetensis. Ann. NY Acad. Sci. 266: 497-512.

IsAKovA N.P. 2011: [The nature of the germinal mass (gonad) in trematode parthenithae (Trematoda)]. Parazitologiya 45: 438448. (In Russian.)

Kechemir N., Théron A., 1980: Existence of replicating sporocysts in the development cycle of Schistosoma haematobium. J. Parasitol. 66: 1068-1070.

KøIE M. 1982: The redia, cercaria and early stages of Aporocotyle simplex Odhner, 1900 (Sanguinicolidae) - a digenetic trematode which has a polychaete annelid as the only intermediate host. Ophelia 21: 115-145.

Leung T.L.F., Poulin R. 2011: Small worms, big appetites: ratios of different functional morphs in relation to interspecific competition in trematode parasites. Int. J. Parasitol. 41: 1063-1068.

LiE K.J. 1967: Antagonism of Paryphostomum segregatum rediae to Schistosoma mansoni sporocysts in the snail Biomphalaria glabrata. J. Parasitol. 53: 969-976.

LIE K.J. 1969: Role of immature rediae in antagonism of Paryphostomum segregatum to Schistosoma mansoni and larval development in degenerated sporocysts. Z. Parasitenkd. 32: 316-323.

LIE K.J. 1973: Larval trematode antagonism: principles and possible application as a control method. Exp. Parasitol. 33: 343-349.

Lim H.K., Heyneman D. 1972: Intramolluscan inter-trematode antagonism: a review of factors influencing the host-parasite system and its possible role in biological control. Adv. Parasitol. 10: 191-268.

Lloyd M.M., Poulin R. 2012: Fitness benefits of a division of labour in parasitic trematode colonies with and without competition. Int. J. Parasitol. 42: 939-946.

Lloyd M.M., Poulin R. 2013: Reproduction and caste ratios under stress in trematode colonies with a division of labour. Parasitology 140: 825-832.

Lloyd M.M., Poulin R. 2014: Geographic variation in caste ratio of trematode colonies with a division of labour reflect local adaptation. Parasitol. Res. 113: 2593-2602. 
MiURA O. 2012: Social organization and caste formation in three additional parasitic flatworm species. Mar. Ecol. Progr. Ser. 465 119-127.

Mouritsen K.N., Halvorsen F.J. 2015: Social flatworms: the minor caste is adapted for attacking competing parasites. Mar. Biol. 162: 1503-1509.

Newey P., Keller L. 2010: Social evolution: war of the worms. Curr. Biol. 20: R985-987.

Nielsen S.S., Johansen M., Mouritsen K.N. 2014: Caste formation in larval Himasthla elongata (Trematoda) infecting common periwinkles Littorina littorea. J. Mar. Biol. Ass. UK 94: 917-923.

Podvyaznaya I.M., Galaktionov K.V. 2014: Trematode reproduction in the molluscan host: an ultrastructural study of the germinal mass in the rediae of Himasthla elongata (Mehlis, 1831) (Digenea: Echinostomatidae). Parasitol. Res. 113: 1215-1224.

REYNOLDS E.S. 1963: The use of lead citrate at high $\mathrm{pH}$ as an electron-opaque stain in electron microscopy. J. Cell Biol. 17: 208-212.

Rondelaud D., Belfaiza M., Vignoles P., Moncef M., DreyFUSS G. 2009: Redial generations of Fasciola hepatica: a review. J. Helminthol. 83: 245-254.

Rondelaud D., Vignoles P., Dreyfuss G. 2004: Fasciola hepatica: the developmental patterns of redial generations in naturally-infected Galba truncatula. Parasitol. Res. 94: 183-187.

Received 14 July 2015

Accepted 29 September 2015
Sсотт D.W. 1979: On optimal and data-based histograms. Biometrika 66: 605-610.

Sokal R.R., Rohlf F.J. 1995: Biometry. Third Edition. W.H. Freeman, New York, 366 pp.

TAFT S.J. 1973: Some aspects of the larval development of Cyclocoelum obscurum (Trematoda: Cyclocoelidae). J. Parasitol. 59: 90-93.

Taft S.J., Heard R.W. 1978: Aspects of the larval development of Ophthalmophagus sp. (Trematoda: Cyclocoelidae). J. Parasitol. 64: 597-600.

ThÉron A. 1981: Dynamics of larval populations of Schistosoma mansoni in Biomphalaria glabrata I. Rhythmic production of cercariae in monomiracidial infection. Ann. Trop. Med. Parasitol. 75 : 71-77.

Touassem R., Théron A. 1986: Study on the intramolluscal development of Schistosoma bovis: demonstration of three patterns of sporocystogenesis by daughter sporocysts. Parasitology 92: $337-341$.

ZIKMUNDOvÁ J. 2011: Is there a soldier cast in freshwater echinostome trematodes? Bc Thesis, Faculty of Science, University of South Bohemia in České Budějovice, Czech Republic, 36 pp.

Zoology: CoOperative Flatworms 2010. Nature 467, Research Highlights: 371

Cite this article as: Galaktionov K.V., Podvyaznaya I.M., Nikolaev K.E., Levakin I.A. 2015: Self-sustaining infrapopulation or colony? Redial clonal groups of Himasthla elongata (Trematoda: Echinostomatidae) in Littorina littorea (Gastropoda: Littorinidae) do not support the concept of eusocial colonies in trematodes. Folia Parasitol. 62: 067. 